\title{
Performance Access of Various Ann Layers in Cognitive Radio Network
}

\author{
Pravin Akula, S N Lakshmipathiraju
}

\begin{abstract}
In this section, the taxonomy outcomes attained by the signal classification system defined in the preceding section are deliberated. To examine the performance, 400 signals were produced and modulated by means of three modulation systems: BPSK, OPSK and OAM. They are transmitted via AWGN channel with $0 d B, 1 d B, 5 d B$ and $10 d B$ noise density. By means of temporal and spectral features with ANN classifier, a sum of 5, 10, 15, 20 and 25 hidden layers are taken for the modulation of the signals. 300 signals are employed for training, and 100 signals are tested with ANN classifier with dissimilar distance measures, Euclidean, city block, cosine and correlation.
\end{abstract}

Keywords: AWGN, QPSK, QAM, ANN and BPSK.

\section{INTRODUCTION}

The cosine distance between two points $u=\left(x_{1}, x_{2}, x_{3}, \ldots x_{n}\right)$ and $v=\left(y_{1}, y_{2}, y_{3}, \ldots y_{n}\right)$ is computed using the eqn. (1) [1,2]

$\operatorname{COSINE}(X, Y)=\frac{\sum_{i} x_{i} y_{i}}{\sqrt{\sum_{i} x_{i}^{2}} \sqrt{\sum_{i} y_{i}^{2}}}$

The correlation distance between two points $u=\left(x_{1}, x_{2}, x_{3}, \ldots x_{n}\right)$ and $v=\left(y_{1}, y_{2}, y_{3}, \ldots y_{n}\right)$ is computed using the eqn. (2) $[3,4]$

$$
r=\frac{N \sum x y-\left(\sum x\right)\left(\sum y\right)}{\sqrt{\left[N \sum x^{2}-\left(\sum x\right)^{2}\right]\left[N \sum y^{2}-\left(\sum y\right)^{2}\right]}}
$$

\section{ANALYSIS BY ANN WITH 5 HIDDEN LAYERS}

The results of ANN with 5 hidden layers with distance measures of Euclidean are presented. Tables $2.1-2.4$ represents Confusion Matrix (CM) attained by the system using Euclidean distance in ANN classifier.

Table 2.1 CM of ANN with 5 hidden layers at $0 \mathrm{~dB}$

\begin{tabular}{|l|l|l|l|}
\hline $\begin{array}{l}\text { Type of } \\
\text { Modulation }\end{array}$ & BPSK & QPSK & QAM \\
\hline BPSK & 62 & 35 & 6 \\
\hline QPSK & 28 & 50 & 24 \\
\hline QAM & 10 & 15 & 70 \\
\hline
\end{tabular}

Revised Manuscript Received on September 10, 2019.

Pravin Akula, Professor, Electronics and Communication Engineering, BVC Engineering College, AndhraPradesh, India.

S N Lakshmipathiraju, Professor, Electronics and Communication Engineering, BVC Engineering College, AndhraPradesh, India.
Table 2.2 CM of ANN with 5 hidden layers at $1 \mathrm{~dB}$

\begin{tabular}{|l|l|l|l|}
\hline Type of Modulation & BPSK & QPSK & QAM \\
\hline BPSK & 74 & 10 & 12 \\
\hline QPSK & 7 & 82 & 10 \\
\hline QAM & 19 & 8 & 78 \\
\hline
\end{tabular}

Table 2.3 CM of ANN with 5 hidden layers at $5 \mathrm{~dB}$

\begin{tabular}{|l|l|l|l|}
\hline Type of Modulation & BPSK & QPSK & QAM \\
\hline BPSK & 85 & 3 & 6 \\
\hline QPSK & 10 & 87 & 6 \\
\hline QAM & 5 & 10 & 88 \\
\hline
\end{tabular}

Table 2.4 CM of ANN with 5 hidden layers at $10 \mathrm{~dB}$

\begin{tabular}{|l|l|l|l|}
\hline Type of Modulation & BPSK & QPSK & QAM \\
\hline BPSK & 88 & 6 & 7 \\
\hline QPSK & 4 & 92 & 3 \\
\hline QAM & 8 & 2 & 90 \\
\hline
\end{tabular}

Figure 2.1 signifies the attained accuracy of the signal classification system at dissimilar noise density using Euclidean distance in ANN classifier.

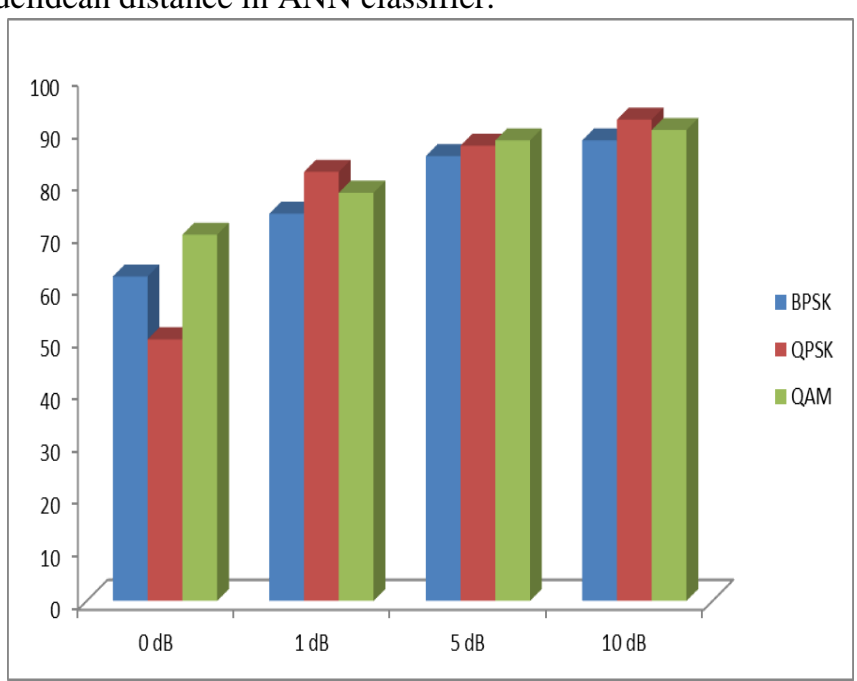

Figure 2.1 Classification accuracy of the signal classification using Euclidean distance in ANN classifier with 5 hidden layers

\section{ANALYSIS BY ANN WITH 10 HIDDEN LAYERS \& RESULTS}

The results of ANN with 10 hidden layers with distance measures of Euclidean are presented. The following Tables 3.1 to 3.4 show the $\mathrm{CM}$ obtained by the system using Euclidean distance in ANN classifier.

Published By:

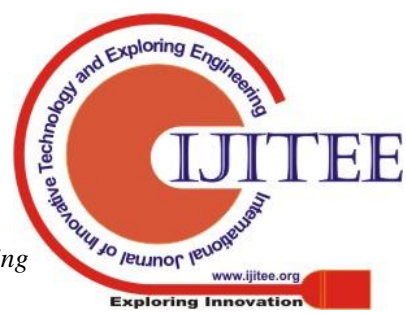


Table 3.1 CM of ANN with 10 hidden layers at $0 \mathrm{~dB}$

\begin{tabular}{|l|l|l|l|}
\hline Type of Modulation & BPSK & QPSK & QAM \\
\hline BPSK & 68 & 20 & 7 \\
\hline QPSK & 12 & 55 & 20 \\
\hline QAM & 20 & 25 & 73 \\
\hline
\end{tabular}

Table 3.2 CM of ANN with 10 hidden layers at $1 \mathrm{~dB}$

\begin{tabular}{|l|l|l|l|}
\hline Type of Modulation & BPSK & QPSK & QAM \\
\hline BPSK & 77 & 10 & 8 \\
\hline QPSK & 3 & 84 & 6 \\
\hline QAM & 20 & 6 & 86 \\
\hline
\end{tabular}

Table 3.3 CM of ANN with 10 hidden layers at $5 \mathrm{~dB}$

\begin{tabular}{|l|l|l|l|}
\hline Type of Modulation & BPSK & QPSK & QAM \\
\hline BPSK & 88 & 6 & 7 \\
\hline QPSK & 2 & 85 & 3 \\
\hline QAM & 10 & 9 & 90 \\
\hline
\end{tabular}

Table 3.4 CM of ANN with 10 hidden layers at $10 \mathrm{~dB}$

\begin{tabular}{|l|l|l|l|}
\hline Type of Modulation & BPSK & QPSK & QAM \\
\hline BPSK & 92 & 3 & 4 \\
\hline QPSK & 4 & 94 & 6 \\
\hline QAM & 4 & 3 & 90 \\
\hline
\end{tabular}

Figure 3.1 represents the attained accuracy of the signal classification system at dissimilar noise density using Euclidean distance in ANN classifier.

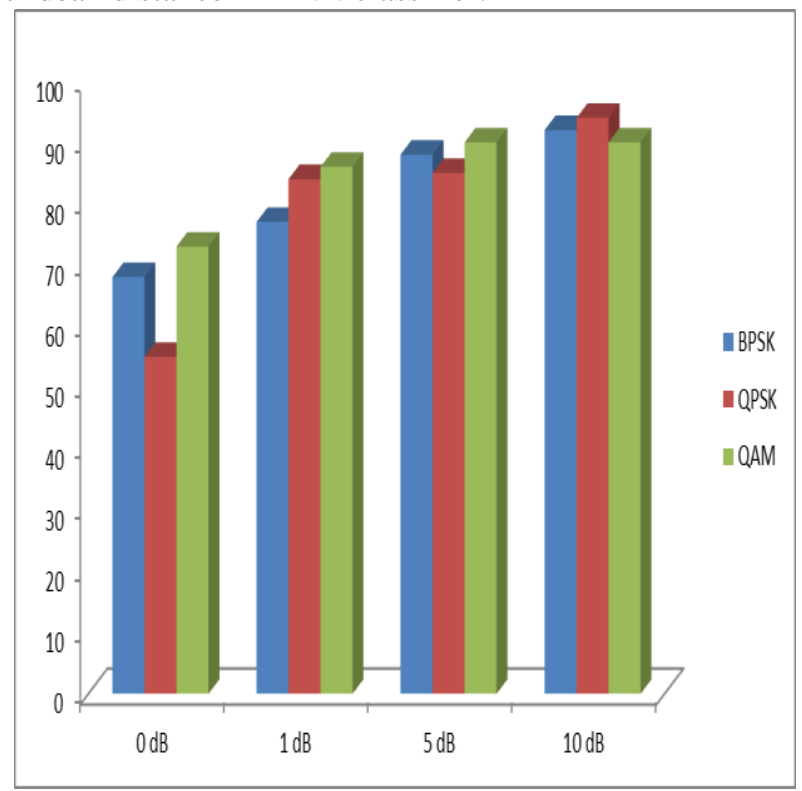

Figure 3.1 Classification accuracy of the signal classification using Euclidean distance in ANN classifier with 10 hidden layers

\section{ANALYSIS BY ANN WITH 15 HIDDEN LAYERS}

The results of ANN with 10 hidden layers with distance measures of Euclidean are presented. The following Tables 4.1 to 4.4 show the CM obtained by the system using Euclidean distance in ANN classifier.

Table 4.1 CM of ANN with 15 hidden layers at $0 \mathrm{~dB}$

\begin{tabular}{|l|l|l|l|}
\hline Type of Modulation & BPSK & QPSK & QAM \\
\hline BPSK & 75 & 5 & 3 \\
\hline QPSK & 20 & 85 & 2 \\
\hline QAM & 5 & 10 & 95 \\
\hline
\end{tabular}

Table 4.2 CM of ANN with 15 hidden layers at $1 \mathrm{~dB}$

\begin{tabular}{|l|l|l|l|}
\hline Type of Modulation & BPSK & QPSK & QAM \\
\hline BPSK & 85 & 10 & 3 \\
\hline QPSK & 5 & 88 & 3 \\
\hline QAM & 10 & 2 & 94 \\
\hline
\end{tabular}

Table 4.3 CM of ANN with 15 hidden layers at $5 \mathrm{~dB}$

\begin{tabular}{|l|l|l|l|}
\hline Type of Modulation & BPSK & QPSK & QAM \\
\hline BPSK & 92 & 2 & 2 \\
\hline QPSK & 4 & 96 & 3 \\
\hline QAM & 4 & 2 & 95 \\
\hline
\end{tabular}

Table 4.4 CM of ANN with 15 hidden layers at $10 \mathrm{~dB}$

\begin{tabular}{|l|l|l|l|}
\hline Type of Modulation & BPSK & QPSK & QAM \\
\hline BPSK & 100 & 1 & 0 \\
\hline QPSK & 0 & 98 & 1 \\
\hline QAM & 0 & 1 & 99 \\
\hline
\end{tabular}

Figure 4.1 represents the attained accuracy of the signal classification scheme at dissimilar noise density using Euclidean distance in ANN classifier.

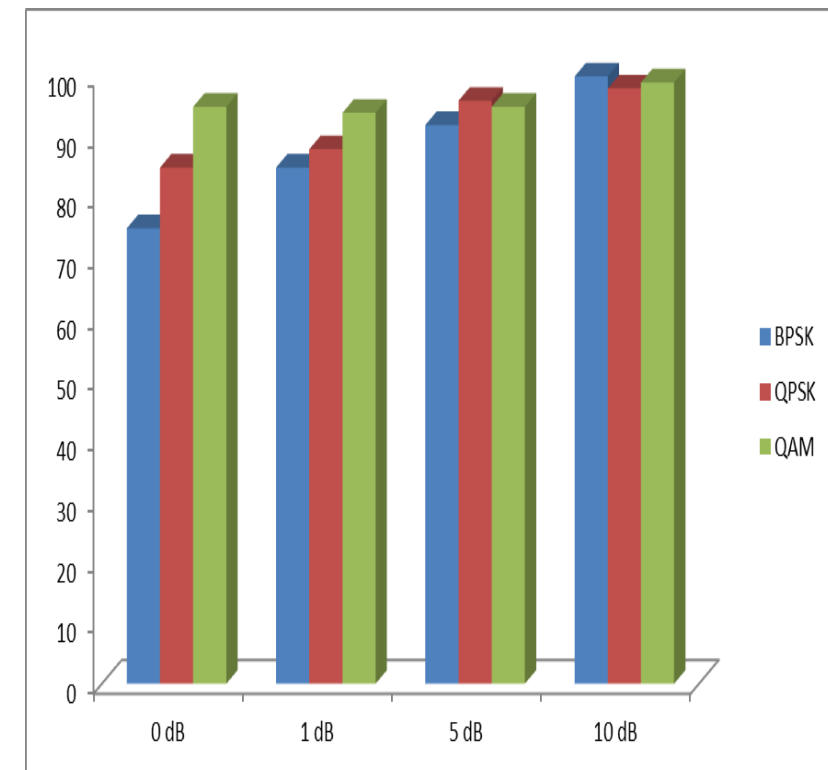

Figure 4.1 Classification accuracy of the signal classification using Euclidean distance in ANN classifier with 10 hidden layers

\section{ANALYSIS BY ANN WITH 20 HIDDEN LAYERS}

The results of ANN with 10 hidden layers with distance measures of Euclidean are presented. Tables 5.1 - 5.4 signify $\mathrm{CM}$ attained by the scheme using Euclidean distance in ANN classifier.

Table 5.1 CM of ANN with 20 hidden layers at $0 \mathrm{~dB}$

\begin{tabular}{|l|l|l|l|}
\hline Type of Modulation & BPSK & QPSK & QAM \\
\hline BPSK & 72 & 15 & 5 \\
\hline QPSK & 20 & 82 & 5 \\
\hline QAM & 8 & 3 & 90 \\
\hline
\end{tabular}


Table 5.2 CM of ANN with 20 hidden layers at $1 \mathrm{~dB}$

\begin{tabular}{|l|l|l|l|}
\hline Type of Modulation & BPSK & QPSK & QAM \\
\hline BPSK & 82 & 10 & 7 \\
\hline QPSK & 2 & 80 & 3 \\
\hline QAM & 10 & 10 & 90 \\
\hline
\end{tabular}

Table 5.3 CM of ANN with 20 hidden layers at $5 \mathrm{~dB}$

\begin{tabular}{|l|l|l|l|}
\hline Type of Modulation & BPSK & QPSK & QAM \\
\hline BPSK & 90 & 4 & 3 \\
\hline QPSK & 5 & 92 & 4 \\
\hline QAM & 5 & 4 & 93 \\
\hline
\end{tabular}

Table 5.4 CM of ANN with 20 hidden layers at $10 \mathrm{~dB}$

\begin{tabular}{|l|l|l|l|}
\hline Type of Modulation & BPSK & QPSK & QAM \\
\hline BPSK & 95 & 2 & 0 \\
\hline QPSK & 5 & 96 & 6 \\
\hline QAM & 0 & 2 & 94 \\
\hline
\end{tabular}

Figure 5.1 represents the attained accuracy of the signal classification scheme at dissimilar noise density using Euclidean distance in ANN classifier.

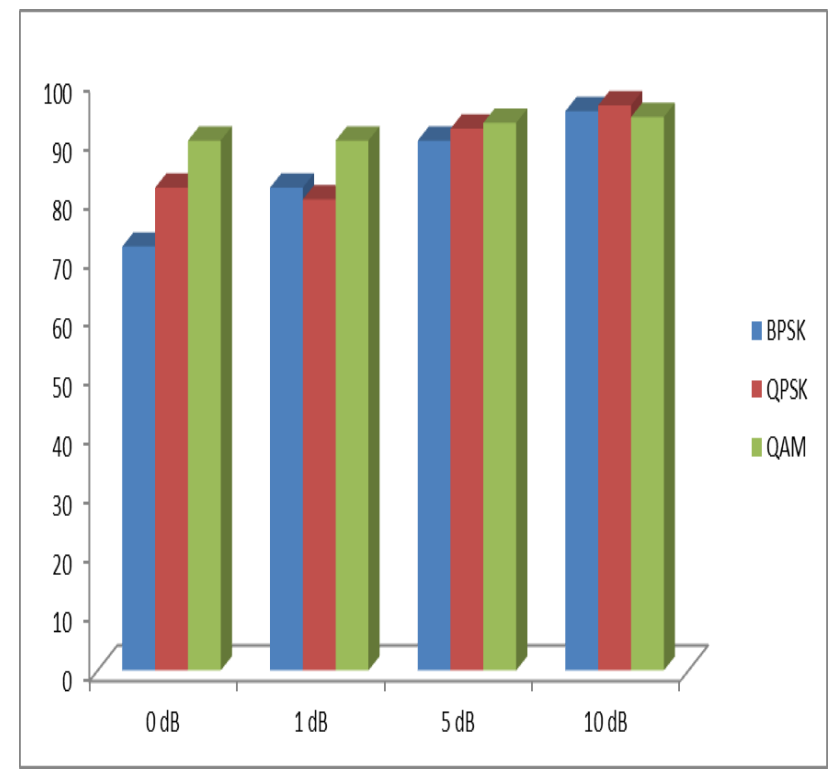

Figure 5.1 Classification accuracy of the signal classification using Euclidean distance in ANN classifier with 20 hidden layers

\section{ANALYSIS BY ANN WITH 25 HIDDEN LAYERS}

The results of ANN with 25 hidden layers with distance measures of Euclidean are presented. The following Tables 6.1 to 6.2 show the $\mathrm{CM}$ obtained by the system using Euclidean distance in ANN classifier.

Table 6.1 CM of ANN with 25 hidden layers at $0 \mathrm{~dB}$

\begin{tabular}{|l|l|l|l|}
\hline Type of Modulation & BPSK & QPSK & QAM \\
\hline BPSK & 70 & 10 & 2 \\
\hline QPSK & 10 & 80 & 10 \\
\hline QAM & 20 & 10 & 88 \\
\hline
\end{tabular}

Table 6.2 CM of ANN with 25 hidden layers at $1 \mathrm{~dB}$

\begin{tabular}{|l|l|l|l|}
\hline Type of Modulation & BPSK & QPSK & QAM \\
\hline BPSK & 80 & 20 & 2 \\
\hline QPSK & 15 & 78 & 10 \\
\hline QAM & 5 & 2 & 88 \\
\hline
\end{tabular}

Table 6.3 CM of ANN with 25 hidden layers at $5 \mathrm{~dB}$

\begin{tabular}{|l|l|l|l|}
\hline Type of Modulation & BPSK & QPSK & QAM \\
\hline BPSK & 88 & 8 & 4 \\
\hline QPSK & 6 & 90 & 5 \\
\hline QAM & 6 & 2 & 91 \\
\hline
\end{tabular}

Table 6.4 CM of ANN with 25 hidden layers at $10 \mathrm{~dB}$

\begin{tabular}{|l|l|l|l|}
\hline Type of Modulation & BPSK & QPSK & QAM \\
\hline BPSK & 93 & 3 & 4 \\
\hline QPSK & 4 & 94 & 4 \\
\hline QAM & 3 & 3 & 92 \\
\hline
\end{tabular}

Figure 6.1 signifies the attained accuracy of the signal classification scheme at dissimilar noise density using Euclidean distance in ANN classifier.

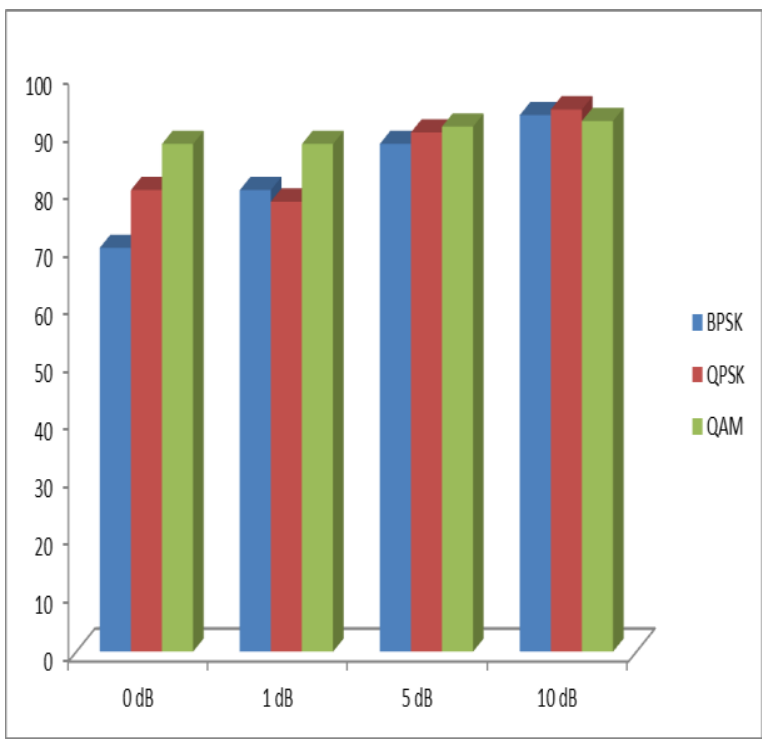

Figure 6.1 Classification accuracy of the signal classification using Euclidean distance in ANN classifier with 25 hidden layers

\section{CONCLUSION}

The simulation results of the proposed OFDM system using BPSK, QPSK and QAM technique are clearly shown with figures and tables. The performance metrics used in this research are BER and throughput. The performance of the proposed system is evaluated in the presence of AWGN and the bit error rates of OFDM/BPSK, OFDM/QPSK and OFDM/16-QAM with convolution codec are derived. In the same way, LDPC and Turbo codec also introduced and BER are computed. Approximately BER is improved by minimum $2 \mathrm{~dB}$ over conventional OFDM system by the proposed OFDM system using BPSK modulated convolution coded signal. For the same convolution coded signal, the improvement of BER is approximately minimum $0.3 \mathrm{~dB}$ and $4.8 \mathrm{~dB}$ for QPSK and QAM modulation respectively. Similarly, the proposed system is tested for turbo and LDPC coded signal. The BER performance for LDPC coded signal is improved by approximately minimum $0.5 \mathrm{~dB}$ over conventional OFDM system for BPSK modulation and minimum $1 \mathrm{~dB}$ for both QPSK and QAM modulation.

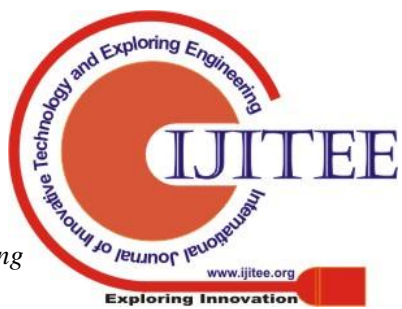




\section{REFERENCES}

1. Zare, T., \& Abouei, J. (2014, September). Kernel-based generalized discriminant analysis for signal classification in cognitive radio. In $7^{\text {th }}$ Int. Sym. on Telecomm. (IST'2014) (pp. 1106-1112). IEEE.

2. Ge, F., Chen, Q., Wang, Y., Bostian, C. W., Rondeau, T. W., \& Le, B. (2008, March). Cognitive radio: From spectrum sharing to adaptive learning and reconfiguration. In 2008 IEEE Aerospace Conf. (pp. 110). IEEE.

3. F. He, X. Xu, L. Zhou and H. Man, "A learning based cognitive radio receiver," 2011 - MILCOM 2011 Military Comm. Conf., 2011, pp. 7-12.

4. Zhao, C., Wang, W., Huang, L., \& Yao, Y. (2009, September). Anti-PUE attack base on the transmitter fingerprint identification in cognitive radio. In $20095^{\text {th }}$ Int. Conf. on Wireless Comm., Netw. and Mobile Comp. (pp. 1-5). IEEE. 